\title{
Variabilidade genética e estimativas de herdabilidade para o caráter germinação em matrizes de Albizia lebbeck
}

\author{
Genetic variability and heritability estimates for the germination trait \\ in Albizia lebbeck parent trees
}

\author{
Flávio Luiz Hilário Rego ${ }^{1}$ Reginaldo Brito da Costa ${ }^{2}$ Adriana Zanirato Contini ${ }^{1}$ \\ Renata Gomez dos Santos Moreno ${ }^{3}$ Karen Gomes da Silva Rondelli ${ }^{3}$ \\ Humberto Haruki Kumimoto ${ }^{3}$
}

\begin{abstract}
Em áreas rurais, buscam-se espécies arbóreas que apresentem rápido crescimento, habilidade para fixar nitrogênio e melhorar a estrutura do solo, especialmente em locais degradados, tendo usos múltiplos e facilidade para consórcio com culturas agrícolas. A Albizia lebbeck apresenta essas características. O presente estudo avaliou a variabilidade genética e estimou parâmetros genéticos em progênies de albizia para o caráter germinação. Sementes de 26 matrizes da espécie foram coletadas no município de Campo Grande, MS. Os testes de superação da dormência e germinação foram realizados no laboratório de Botânica da Universidade Católica Dom Bosco. O delineamento experimental foi o de blocos ao acaso, com cinco repetições e 15 plantas. As estimativas de herdabilidade no sentido amplo foram de 0,43 para indivíduos e 0,79 para média de matrizes, sugerindo expressivo controle genético. A seleção das 10 melhores matrizes proporcionou ganho genético de, pelo menos, 8,1\%. Este germoplasma pode ser usado em programa de melhoramento genético para a espécie.
\end{abstract}

Palavras-chave: Albizia lebbeck, variabilidade genética, germinação, herdabilidade, seleção.

\section{ABSTRACT}

Fast growing and nitrogen fixing forest trees species play an important role in rural areas, mainly in degraded lands, where they provide multiple purposes and facilities for intercropping with other crops. Albizia lebbeck is one of such species. This paper aimed at estimating the genetic variability for germination in a progeny test of this species. Seeds from 26 parent trees were collected in a site located at Campo Grande, MS. The germination tests were performed in the UCDB University under a randomised complete block design with five replications and 15 plants per plot. The broad sense heritability estimates were 0.43 and 0.79 at individual and parent tree mean levels, respectively, which denotes a moderate to high genetic control. Selection of the best 10 parents provided a genetic gain of $8.1 \%$. This genetic resource can be used in a genetic improvement program for the species.

Key words: Albizia lebbeck, genetic variability, germination, heritability, selection.

A albizia (Albizia lebbeck) é uma espécie arbórea da família Leguminosae - mimosoideae, nativa da Ásia tropical e caracteriza-se por apresentar um rápido crescimento, habilidade para fixar nitrogênio e melhorar a estrutura do solo, especialmente em áreas degradadas, tendo usos múltiplos e facilidade para consórcio com culturas agrícolas. Lewis (1987) ressalta que, devido ao seu amplo cultivo e plasticidade, espalhou-se pelos trópicos. A utilização do gênero

\footnotetext{
${ }^{1}$ Programa de Mestrado em Desenvolvimento Local da Universidade Católica Dom Bosco (UCDB), Campo Grande, MS, Brasil. ${ }^{2}$ Engenheiro Florestal, DSc, Programa de Mestrado em Desenvolvimento Local da UCDB, Av. Tamandaré, 6000, Jd. Seminário, CP 100, 79117-900, Campo Grande, MS, Brasil. E-mail: rcosta@ucdb.br.

${ }^{3}$ Curso de Biologia da UCDB, Campo Grande, MS, Brasil.
} 
Albizia em Sistemas Agroflorestais (SAFs), tem sido recomendada em função da utilização da madeira para várias finalidades, como melhoradora de solo e na alimentação animal (LORENZI, 1998). Além destas características, a espécie pode ser utilizada como árvore ornamental, especialmente em áreas urbanas (SERRANO, 2000).

A despeito da reconhecida importância e ampla utilização da espécie, ainda persiste uma carência de informações sobre diversos aspectos. Portanto, estudos de variabilidade deste germoplasma são importantes, tendo em vista um melhor planejamento de futuros programas de melhoramento genético. Diversos trabalhos nesta linha com diferentes espécies vegetais têm sido realizados com indivíduos estabelecidos no campo, como seringueira (COSTA et al., 2000a; COSTA et al., 2000b), cacau (RESENDE \& DIAS, 2000), acerola (PAIVA et al., 2002) e pupunha (FARIAS NETO \& RESENDE, 2001), dentre outros.

As sementes de albizia apresentam dormência tegumentar, porém ainda são escassas as informações sobre a variabilidade genética relacionada ao processo germinativo em função da dormência tegumentar. A germinação das sementes pode ser considerada como a retomada do crescimento do embrião com o subseqüente rompimento do tegumento pela radícula (CARVALHO \& NAKAGAWA, 1983). Portanto, a quebra da quiescência ou dormência, representa o reinício das atividades metabólicas (NASSIF et al., 2000). O presente estudo objetivou avaliar a variabilidade genética e estimar os parâmetros genéticos para germinação de diferentes progênies de albizia.

As sementes que constituem o material genético deste estudo foram coletadas de 26 matrizes de A. lebbeck no município de Campo Grande, MS, localizado na latitude $20^{\circ} 26^{\prime} 34^{\prime}$ 'S, longitude $50^{\circ} 38^{\prime}$ 47” W e altitude $480 \mathrm{~m}$. Os testes de superação e germinação foram realizados no laboratório de Botânica da Universidade Católica Dom Bosco (UCDB). Para a avaliação do percentual germinativo das sementes, utilizou-se câmara de germinação do tipo Mangelsdolf, a uma temperatura de $28^{\circ} \mathrm{C}$. Usou-se como substrato para germinação o papel toalha germitest. O delineamento experimental empregado foi de blocos casualizados, com 26 tratamentos, 5 repetições e 15 plantas por parcela. Para a superação da dormência, fez-se imersão das sementes em água quente por 10 minutos. A avaliação da germinação ocorreu diariamente, até o 15ำ dia e em dias alternados, até completar dois meses. As sementes foram consideradas germinadas ao emitirem radícula e os resultados foram tabulados em médias de germinação por parcela.
Para a análise das variáveis, utilizou-se o modelo estatístico que considera todos os efeitos aleatórios (exceto a média), consistindo do seguinte: $\mathrm{Y}_{\mathrm{ijk}}=\mathrm{m}+\mathrm{p}_{\mathrm{i}}+\mathrm{b}_{\mathrm{i}}+\mathrm{e}_{\mathrm{ij}}+\mathrm{d}_{\mathrm{ijk}}$ onde: $\mathrm{Y}_{\mathrm{ijk}}$ : observação relativa à planta $\mathrm{k}$, na matriz' $\mathrm{i}$, no bloco $\mathrm{j}$; $\mathrm{m}$ : média geral; $p_{i}$ : efeito da matriz $i$; $b_{j}$ : efeito do bloco $j$; $e_{i j}$ : erro experimental associado à parcela $\mathrm{ij} ; \mathrm{d}_{\mathrm{ijk}}$ : efeito do indivíduo $\mathrm{k}$ dentro da parcela ij. As estimativas de parâmetros genéticos e fenotípicos foram obtidas através do software genético-estatístico denominado SELEGEN - REML/BLUP, desenvolvido por RESENDE (2002) para o melhoramento de plantas perenes.

Os coeficientes de herdabilidades (método univariado), componentes de variância genética e fenotípica, média geral, coeficiente de variação experimental e coeficiente de variação genética são apresentados na tabela 1 . Os valores de herdabilidades no sentido amplo para média de matrizes $(0,79)$ e do indivíduo no experimento $(0,43)$ foram altos (Tabela 1$)$. Os valores de herdabilidade obtidos nas progênies sugerem grandes possibilidades de ganho genético, tendo em vista que o progresso esperado com a seleção depende da herdabilidade do caráter, da intensidade de seleção e, do desvio padrão fenotípico do caráter (DUDLEY \& MOLL, 1969). É importante ressaltar que o parâmetro herdabilidade corresponde à proporção da variabilidade total que é de natureza genética, ou o quociente entre a variância genética e a variância total (WRIGHT, 1976; FALCONER, 1987).

A mais importante função da herdabilidade no estudo genético do caráter métrico é o seu papel preditivo expressando a confiança do valor fenotípico como um guia para o valor genético, ou o grau de correspondência entre o valor fenotípico e o valor genético (FALCONER, 1987). O autor salienta ainda, que a herdabilidade é uma propriedade não somente de um caráter, mas também da população e das circunstâncias de ambiente às quais os indivíduos estão sujeitos. Uma vez que o valor da herdabilidade depende da magnitude de todos os componentes da variância, uma alteração em qualquer um deles afetará o valor da herdabilidade. Portanto, os componentes da variância, as herdabilidades e, ainda, as acurácias são imprescindíveis na determinação dos métodos mais eficientes de seleção a serem utilizados nos programas de melhoramento (RESENDE et al., 1995).

O coeficiente de variação experimental (CVe\%) obtido para o caráter germinação de sementes $(12,84 \%)$, pode ser considerado baixo e demonstra boa precisão para o ensaio e para critério de avaliação. O coeficiente de variação genética (CVg\%), que expressa

Ciência Rural, v.35, n.5, set-out, 2005. 
Tabela 1 - Estimativas dos coeficientes de herdabilidade no sentido amplo, variâncias genéticas e fenotípicas para o caráter germinação de sementes de Albizia lebbeck.

\begin{tabular}{lc}
\hline Efeitos & Estimativas \\
\hline Herdabilidade média das matrizes $\left(\hat{\left.h_{m m}\right)}\right.$ & 0,79 \\
Herdabilidade individual no sentido amplo dos efeitos genotípicos $\left(h_{g}\right)$ & 0,43 \\
Variância residual ambiental $\left(\sigma_{e}^{2}\right)$ & 126,79 \\
Variância genotípica entre matrizes $\left(\sigma_{g}^{2}\right)$ & 96,74 \\
Variância fenotípica individual $\left(\sigma_{f}^{2}\right)$ & 223,54 \\
\hline $\begin{array}{l}\text { Média geral } \\
\text { Coeficiente de variação experimental }(\mathrm{CVe} \%)\end{array}$ & 87,70 \\
Coeficiente de variação genética $(\mathrm{CVg} \%)$ & 12,84 \\
\hline
\end{tabular}

em porcentagem da média geral a quantidade de variação genética existente, apresentou valor (11,27\%), também baixo, o que denota que, em futuras avaliações em campo, poderá haver maior expressão de variação genética para outros caracteres.

Constata-se que as matrizes 26, 03, 12 e 22 apresentaram os melhores desempenhos com valores genéticos idênticos, porém deve-se considerar também os valores expressivos das matrizes 18, 25 e 09. Os valores genéticos variaram de 97,45 a 93,01, e podem ser considerados substanciais em se tratando de um teste de germinação de sementes, conforme Tabela 2. Essencialmente a seleção atua promovendo a alteração das freqüências alélicas nos locos que controlam o caráter sob seleção, conduzindo a alteração na média genotípica da população.

Tabela 2 - Efeito genotípico (EG), valor genotípico (VG), ganho genético (\%) e nova média de população para o caráter germinação das 10 melhores progênies e acurácia seletiva de Albizia lebbeck.

\begin{tabular}{rcccc}
\hline Matriz & EG & VG & $\begin{array}{c}\text { Ganho } \\
\text { Genético (\%) }\end{array}$ & $\begin{array}{c}\text { Nova } \\
\text { média }\end{array}$ \\
\hline 26 & 9,75 & 97,45 & 9,75 & 97,45 \\
3 & 9,75 & 97,45 & 9,75 & 97,45 \\
12 & 9,75 & 97,45 & 9,75 & 97,45 \\
22 & 9,75 & 97,45 & 9,75 & 97,45 \\
18 & 8,64 & 96,34 & 9,52 & 97,22 \\
25 & 8,64 & 96,34 & 9,38 & 97,08 \\
9 & 7,53 & 95,23 & 9,11 & 96,81 \\
8 & 6,42 & 94,12 & 8,77 & 96,47 \\
2 & 5,47 & 93,17 & 8,41 & 96,11 \\
20 & 5,31 & 93,01 & 8,10 & 95,80 \\
\hline Acurácia seletiva & & & & 0,89 \\
\hline
\end{tabular}

A correlação entre os valores preditos e os observados equivale, em média, a 0,89 podendo ser considerada alta. Portanto, os valores preditos permitem indicar com mais segurança que o germoplasma em estudo maximizará as possibilidades de progresso genético com seleção. De maneira geral, os valores genéticos preditos não são iguais aos valores genéticos verdadeiros dos indivíduos. A proximidade entre estes dois valores pode ser avaliada com base na estatística denominada acurácia (VAN VLECK et al., 1987). A literatura prática pertinente ao assunto tem demonstrado a importância da acurácia para demonstrar o grau de confiabilidade dos resultados obtidos na avaliação genética (RESENDE et al., 1995; COSTA et al., 2000).

\section{REFERÊNCIAS}

CARVALHO, N.M.; NAKAGAWA, J. Sementes: ciência, tecnologia e produção. 2.ed. Campinas : Fundação Cargil. 1983. 429p.

COSTA, R.B. et al. Selection and genetic gain in populations of Hevea brasiliensis with a mixed mating system. Genetics and Molecular Biology, v.23, p.671-679, 2000a.

COSTA, R.B. et al. Maximization of genetic gain in rubber tree (Hevea) breeding with effective size restriction. Genetics and Molecular Biology, v.23, n.2, p.457-462, 2000b.

DUDLEY. J.W.; MOLL, R.H. Interpretation and use of estimation of heritability and genetic varience in plant breeding. Crop Science, Madison v.2, n.3, p.257-262, 1969.

FALCONER, D.S. Introdução à genética quantitativa. Viçosa : Universidade Federal de Viçosa, 1987. 279p.

FARIAS NETO, J.T; RESENDE, M.D.V. de. Aplicação da metodologia de modelos mistos (REML/BLUP) na estimação 
de componentes de variância e predição de valores genéticos em pupunheira (Bactris gasipaes L.). Revista Brasileira de Fruticultura, v.23. n.2. p.320-324, 2001.

LEWIS, G.P. Legumes of Bahia. Kew : Royal Botanic Gardens, 1987. 369p.

LORENZI, H. Árvores brasileiras: manual de identificação e cultivo de plantas arbóreas nativas do Brasil. 2.ed. Nova Odessa, SP : Plantarum, 1998. 352p.

NASSIF, S.M.L. et al. Germinação de sementes: fatores externos (ambientais) que influenciam na germinação. Capturado em 25 nov. 2000. Online. Disponível na Internet: http://ipef.br/espécies/germinaçãoambiental.

PAIVA, J.R. et al. Índice multi-efeitos (BLUP) e estimativas de parâmetros genéticos aplicados ao melhoramento da acerola. Pesquisa Agropecuária Brasileira, v.37, n.6, p.799-807, 2002.

RESENDE, M.D.V. et al. Acurácia seletiva, intervalos de confiança e variância de ganhos genéticos associados a 22 métodos de seleção em Pinus caribaea var. hondurensis. Revista Floresta, Curitiba, v.24, n.1/2, p.35-45, 1995.

RESENDE, M.D.V.; DIAS, L.A.S. Aplicação da metodologia de modelos mistos (REML/BLUP) na estimação de parâmetros genéticos e predição de valores genéticos aditivos e genotípicos em espécies frutíferas. Revista Brasileira de Fruticultura, v.22, n.1, p.44-52, 2000.

RESENDE, M.D.V. Software SELEGEN - REML/BLUP Colombo : Embrapa Florestas, 2002. 67p. (Embrapa Florestas. Documentos, 77).

SERRANO, M.A. Dispersão de Albizia lebbeck (L.) Benth em área urbana - Cuiabá, MT. Revista Agricultura Tropical, Cuiabá, v.4, n.1, p.112-117, 2000.

VAN VLECK, L.D. et al. Genetics for the animal sciences. New York :W.H. Freeman, 1987. 391p.

WRIGHT, J.W. Introduction to forest genetics. New York: Academic, 1976. 463p. 